\title{
Lung Cancer Screening: Adjuncts and Alternatives to Low-Dose CT Scans
}

\author{
Rolando Sanchez Sanchez $\cdot$ Nichole T. Tanner • \\ Nasar A. Siddiqi · Gerard A. Silvestri
}

Published online: 17 October 2013

(C) Springer Science + Business Media New York 2013

\begin{abstract}
Lung cancer (LC) is the leading cause of cancer related mortality in US. The National Lung Screening Trial has demonstrated a mortality benefit of using low-dose computed tomography (LDCT) in the screening of LC in high-risk individuals. The US Preventive Service Task Force has given screening for LC with LDCT a grade B recommendation; however, it recognizes gaps in generalizability to the population that would qualify for screening. There are a number of new tests in various stages of evaluation and development that hold promise as adjuncts or alternatives to LDCT. The following is a review of these novel diagnostic tests.
\end{abstract}

Keywords Lung cancer - Low-dose CT scan - Exhaled breath analysis - Airway epithelial - Gene expression biomarkers · Volatile organic compounds

\section{Introduction}

Lung cancer (LC) is the leading cause of cancer-related mortality in the US, causing more deaths than breast, prostate and colon cancer combined [1]. The median 5 -year survival for all comers in US is $\sim 16 \%$ [1]. The median 5-year survival for stage I and II LC, however, ranges from 50 to $70 \%$, making early detection desirable for decreasing LC mortality [1]. Investigations into

R. S. Sanchez $\cdot$ N. T. Tanner $\cdot$ N. A. Siddiqi

G. A. Silvestri $(\square)$

Division of Pulmonary and Critical Care, Department of Internal Medicine, Allergy and Sleep Medicine, Medical University of South Carolina, 96 Jonathan Lucas Street, Suite 812-G,

Charleston, SC 29425, USA

e-mail: silvestr@musc.edu effective screening with methods including chest radiograph (CXR) and sputum cytology alone and in combination were unable to demonstrate any impact on LC mortality $[2 \bullet \bullet, 3]$.

In 2011, the results from the National Lung Screening Trial (NLST) were published. This was the first large scale multicenter randomized trial that convincingly demonstrated a mortality benefit by screening high-risk individuals with low-dose computed tomography (LDCT) scans [4०•]. The following reviews the evidence and limitations of LC screening with LDCT, and describes the potential use of new techniques in LC screening as adjuncts and alternatives to LDCT.

\section{Low Dose Helical Computed Tomography (LDCT)}

Over the last two decades, technical advances have improved the quality of image acquisition and diagnostic yield of computed tomography (CT). The multidetector helical CT, for example, is able to image the entire lung during a single breath hold, using a lower radiation dose than standard CT. The initial studies demonstrated an increased rate of lung nodule detection and higher percentage of detected early-stage LCs with LDCT compared to CXR. Study design, however, precluded conclusions as to the impact of the use of LDCT in LC mortality, because the studies either lacked a control group, were underpowered, or did not have adequate follow-up time [5-11].

The NLST [4・•] was designed to detect a $20 \%$ reduction in mortality by LDCT LC screening, with a $90 \%$ power. It included 33 centers across the US, and enrolled 53,454 current or former smokers aged 55-74 years, with a minimum 30-pack-year smoking history. Former smokers had quit within the past 15 years. The participants were 
randomly assigned to screening with LDCT ( $n=26,722)$ or CXR $(n=26,732)$ annually for three screens. The LDCT screenings were consider positive if they revealed a noncalcified nodule measuring at least $4 \mathrm{~mm}$ in longest diameter, and CXR screens were positive if they revealed any noncalcified nodule or mass. The median follow-up period was over 6.5 years.

The LDCT-screened group had a higher rate of positive screening tests compared with the CXR group (24.2 vs. $6.9 \%)$. However, the rate of false positive results was high (96.4 \% in the LDCT group and $94.5 \%$ in the CXR group). LDCT detected more LC compared to CXR (1,060 vs. 941). Among the patients diagnosed with LC, the LDCT group had significantly more stage I cancers (63 vs. $47.6 \%)$. There were also fewer patients with stage III and IV LCs in the LDCT group compared to the CXR group (29.8 vs. $43.2 \%$ ). At the end of the follow-up period, there were 354 LC deaths in the LDCT group and 442 deaths in the CXR group. The LC rate mortality was 247 per 100,000 person-years in the LDCT group, and 309 per 100,000 person-years in the CXR group (a $20 \%$ reduction in mortality in the LDCT group). The overall mortality was reduced by $6.7 \%$, largely due to the reduction in deaths from LC. The number needed to screen with low-dose CT to prevent one death from LC was 320 [4••], which is comparable to the number of women needed to screen with mammography to save one life from breast cancer [12].

\section{Potential Shortcomings of LDCT Screening}

\section{Generalizability of NLST Results}

Although randomized controlled studies are considered the most robust method to assess efficacy (performance under ideal conditions), one of their main limitations is their ability to evaluate effectiveness (performance under real conditions). Randomized controlled trials require more standardized and higher levels of medical care than occurs in real practice. In addition, the trial participants are usually not fully representative of the eventual target group [13]. Such is true for the NLST cohort that, when compared to the US population eligible for screening based on trial entry criteria, was younger, healthier, better educated, and more frequently former smokers [4*0]. It is therefore unclear if the same mortality benefit will be recognized with large-scale LC screening implementation.

In the NSLT, screening with LDCT had a high rate of false positive results $(96 \%)$ and low positive predicted value $(<4 \%)$. Despite this, few medical complications occurred during diagnostic evaluation for positive screens $(\sim 1.4 \%)$. This may be due in some part to the location of care in the NLST. Participants were enrolled in urban, tertiary care hospitals with expertise in all aspects of cancer care, including dedicated thoracic radiologists. The majority of positive screens were followed with serial imaging without need for invasive testing. In contrast, community practice gives rise to the potential for considerable variation in the management of solitary pulmonary nodules identified by screening LDCT. One study demonstrated a two-fold variation among geographic regions in the use of CT-guided biopsy, ranging from 14.7 to 36.2 per 100,000 adults $[14 \cdot, 15]$. This variation in management of solitary pulmonary nodules may lead to an increased number of invasive procedures with risk of harm. In addition, the psychological harms of a positive test result should not be underestimated. Studies of breast and prostate cancer screening showed that false-positive screening results were associated with depression and change in selfperception of health status [16, 17].

There are, however, ways to decrease the high falsepositive rate from screening with LDCT. Investigators from the NELSON study [18] improved the sensitivity, specificity, positive and negative predictive value of the LDCT for LC screening through the use of semi-automated volumetric software to measure diameter and volume doubling time (VDT). Growth was defined as a change in volume between the first and the second scan of $25 \%$ or greater. Nodules meeting growth criteria were then classified into three categories based on VDT $(<400,400-600$, and $>600$ days). This approach to nodule management resulted in a decrease in the rate of test-positive results at baseline from 30 to $2 \%$. The final results regarding the reduction in mortality from LC from this trial are pending.

Another difference between the NSLT results and community practice is the mortality rate from LC surgery (1 vs. 3-5 \% national average) $[19,20]$. While the study allowed participants to choose where they had their evaluation and management for screen detected nodules, it is likely that many were managed at an NLST site with high volume and dedicated thoracic surgery support, both of which are associated with better outcomes $[15,19,20]$.

Finally, the NSLT did not assess the impact of LDCT screening in other high-risk populations, including those with chronic obstructive pulmonary disease (COPD), firstdegree relative with LC, occupational exposure to asbestos and other carcinogens, and prior history of LC or other smoking-related cancers. Therefore, it is unknown the degree to which these populations would benefit from LDCT screening.

\section{Overdiagnosis}

Another concern with all screening tests is the possibility of overdiagnosis, defined as the detection of indolent cancers that may have never became symptomatic or 
caused death [21-23]. Overdiagnosis causes an increase in screening costs, overtreatment, and morbidity. It also has the potential to increase mortality from unnecessary diagnostic and therapeutic procedures. This phenomenon is a possibility in LC screening, due to the degree of biologic heterogeneity. For instance, it has been described that ground glass nodules can remain stable for years before becoming aggressive $[24,25]$. There is data suggesting that the use of volumetric measurements of pulmonary nodules like volume double time [26•, 27•]; and pulmonary function tests [28•] might help to better distinguish between aggressive LC and the slow-growing and indolent ones, which could decrease the rate of overdiagnosis and overtreatment. The period of follow-up in the NLST was not long enough to assess the magnitude of this issue, and further follow-up should be revealing.

\section{Barriers to Implementation}

The higher rate of active smokers in the eligible US population represent a potential barrier to LC screening. In a national telephone survey to assess beliefs toward LC screening, it was found that current smokers are less likely to believe that early cancer detection would result in a good chance of survival, and are less likely to consider CT screening for LC [29]. Only half of the current smokers surveyed would opt for surgical resection of a screendetected LC. When these findings are coupled with the fact that smokers make up $31 \%$ of population below the poverty line [30], smokers are likely to be a more difficult-toreach target population for large-scale screening efforts.

\section{Radiation Exposure}

The risk of carcinogenesis related to the radiation from CT imaging is based on organ-specific doses, and individual susceptibility. The mean effective dose per scan in the NLST was 1.6 miliSevers (mSv) for men and $2.1 \mathrm{mSv}$ for women [31•]. These values are almost half the annual radiation exposure in the US $(3 \mathrm{mSv})$, and one-fifth of the dose from a conventional chest CT [32]. According to one study, the radiation exposure from LDCT would confer a risk of LC of $0.85 \%$ in female smokers, and of $0.23 \%$ in male smokers, increasing their baseline risk by $5 \%$ in women and by $1.5 \%$ in men [33]. Finally, the investigators from the NLST, estimated that the radiation risk from CT screening of 55-year-old smokers would result in one to three LC deaths per 10,000 people screened, and 0.3 new breast cancers per 10,000 females [4]. This radiation-related risk is outweighed by the $20 \%$ reduction in mortality by LDCT screening in a high-risk population. It is uncertain if this risk benefit ratio would be less favorable in populations with a lower risk of developing LC.

\section{Cost-Effectiveness}

With the increasing cost of health care, an assessment of cost efficacy is needed prior to widespread LC screening implementation. Cost-effectiveness analysis measures the relative value of a screening method as the incremental economic cost to accomplish a better health outcome [34, 35]. The most commonly used metric unit is the incremental cost-effectiveness ratio per quality adjusted life years (QALYs) gained [34, 35]; <\$50,000-\$100,000 per QALY gained is generally a well-accepted cutoff in the US to suggest an intervention is cost effective [35]. The World Health Organization recommends interventions with a cost effective ratio $<3$ times the gross domestic product (GDP) per capita [35] (about $\$ 49,965$ in the US in 2012, according to the World Bank). Several cost efficacy analyses for LC screening with LDCT have been performed, with broad results ranging from $\$ 2,500$ to $\$ 2$ million per QALYs gained [15, 36-38]. The variability in results can be explained in part by the fact that the cost-effective metric unit is a ratio. An increase in the cost, or a decrease in the effectiveness of the intervention, generates a larger ratio (or less cost effective value). Since the cost of the LDCT screening has a finite limit, the main influencing factor of the cost effective ratio would be the effectiveness of LDCT screening, which is strongly influenced by specific eligibility criteria, as well as the rate of smoking cessation among the participants during the screening [39•]. Interestingly, there has been just one randomized study looking at the rate of smoking cessation at time of LC screening, and it showed no significant difference compared to the control group [40].

The cost-effectiveness analysis from the NLST is currently underway, and the results should be available soon. Even if the results are positive, other programs, like smoking cessation $(\$ 5,000$ per quality-adjusted life-year to implement the AHRQ smoking cessation guidelines), that have been shown to be cost-effective should not be forgotten [41].

Currently, four organizations, including the US Preventive Services Task Force (USPSTF), the American College of Chest Physicians (ACCP), the American Society of Clinical Oncology (ASCO), and the American Cancer Society (ACS), recommend that LDCT should be considered in a population that meets the NLST criteria; the UPSTF extended the upper age limit from 74 to 79 years. They provided a B-level of evidence for this recommendation [22, 42••]. Two other organizations, the National Comprehensive Cancer Network (NCCN) and the American Association for Thoracic Surgery (AATS), expanded their population target, in addition to those who meet the criteria for the NLST, to individuals aged 50 years or older with at least a 20-pack-year history plus 
one defined risk factor for LC (prior LC history, occupational exposure to carcinogens, chronic lung disease, or family history of LC) [22, 42••].

\section{Adjuncts and Alternatives to LDCT Screening}

While screening with LDCT has demonstrated a clear mortality benefit, the aforementioned limitations make adjuncts and alternative testing for LC screening desirable to improve the efficacy of screening with LDCT, and allow for the conservative management of screen detected nodules. These newer diagnostic modalities include exhaled breath analysis, airway epithelial gene expression biomarkers and serum sampling for antibodies.

\section{Breath Analysis}

\section{Volatile Organic Compounds (VOCs)}

A promising area of LC biomarker research is the analysis of volatile organic compounds (VOCs) in the breath. VOCs are organic compounds with a high vapor pressure or volatility that can be detected in the headspace of cancer cells, blood samples, saliva, and in the exhaled breath. There is growing evidence for using exhaled breath VOC analysis in the diagnosis and screening of LC. This relies on the principle that the composition of VOCs in the exhaled breath reflects the metabolic activity within the body. Thus, cancer-related changes in the body's metabolic process and blood chemistry are reflected in measurable changes in the breath through exchange via the lungs [43-45].

The measurement of VOCs is noninvasive, can be repeated in short intervals, and therefore has potential as a screening test. There are different techniques used to analyze VOC in exhaled breath. Mass spectrometry (MS) is probably the most studied technique. It can be done using gas chromatography (GC-MS) or proton transfer reaction (PTR-MS). This technique allows the detection and measurement of specific VOCs. It is very sensitive, but is also more expensive and requires expert interpretation [15, 45]. Other techniques used to analyze VOCs include laser spectrometry, ion mobility spectrometry, differential mobility spectrometry, and sensor arrays. Gaseous chemical sensors devices (also called electronic noses), use chemical vapor sensor arrays that generate a reading based on their interaction with specific components or the entire composition of the breath. The output depends on the type of sensor being used: color, mass, vibration, conductivity, or a combination. They have a high sensitivity, are easy to use, and are portable; however, they are difficult to calibrate, and they do not identify the specific constituents of the exhaled breath [44-46].
In 1985, Gordon and colleagues were the first to described VOCs in exhaled breath of LC patients. Using a gas chromatography-mass spectrometry (GC-MS) system, [47] the breath of 12 LC patients were analyzed and compared with controls. A significant difference in the detected level of three VOCs allowed for a model that had $93 \%$ accuracy in discriminating those with LC [47]. Since then, there have been multiple studies showing that the pattern of VOCs in the exhaled breath could distinguish patients with and without LC, with sensitivities ranging from 71 to $100 \%$ [48-51・, 52-55]. Interestingly, VOCs can be sensed by dogs, which with adequate training can differentiate patients with lung, colon and breast cancer from normal controls, with a sensitivity and specificity above $90 \%[56,57 \bullet, 58]$.

Despite the promising data, the use of VOCs analysis in the breath for the diagnosis of LC has several limitations. Most of these studies have been done in small populations, with significant variation in the type of control group. Data from multicenter trials assessing their broad applicability is needed. In addition, the varying techniques for VOC analysis in the breath create the need for further standardization, including sample collection, processing and analysis. Also, the impact of air pollution, tobacco use, lung ventilation volumes and tissue blood flow in the obtained results needs to be further studied [59-61]. Finally, given the complexity of the histology and biology of LC, it is very difficult to establish a relationship from a specific pattern of VOCs with LC.

\section{Exhaled Breath Condensate (EBC)}

Another noninvasive test being developed for LC detection involves the analysis of nonvolatile compounds in the breath. This is carried out by capturing a breath in a liquid phase, as an exhaled breath condensate (EBC). The breath sample is cooled with ice, dry ice or liquid nitrogen in a condensing chamber. This provides a sample of the fluid layer from the airway epithelium of respiratory tract. Molecules, including like cytokines, DNA, lipid peroxidation products, and nitric oxide metabolites, can then be measured [62, 63].

Chan and colleges [63] found differences in $\mathrm{H} 2 \mathrm{O} 2$ levels in EBC samples from LC patients, smokers, former smokers and non-smokers. Carpagnano et al. [64, 65] also found differences in the presence of microsatellite instability in DNA obtained from EBC of LC patients compared to normal controls. Gessner and colleges [66] found similar results with the presence of P53 mutations in patients with NSLC compared to normal controls. Other studies have demonstrated that interleukin2, TNF alpha, leptin, and endothelin-1 are present in higher levels in the EBC from LC patient compared to normal controls. These levels also 
appeared to correlate with the stage of the disease [67-69]. Like VOCs, EBC still requires further validation and large scale trials.

\section{Serum Biomarkers}

It has been demonstrated that cancer patients develop an autoimmune response with inflammation and possibly tissue damage in response to their tumor. This is believed to be due to circulating serum antibodies known as tumorassociated antigens (TAA) [70]. Current research is focused on developing a selective serologic test that could be used for early detection of occult lung tumors. A panel of six TAAs was validated previously by Boyle et al. [71] This panel included p53, NY_ESO-1, CAGE, SOX 2, and Annexin I, as these have all been implicated in the production of autoantibodies or immune biomarkers in LC. However, the sensitivity and specificity of this panel is 39 and $89 \%$, respectively. A subsequent study has since been done, comparing this six-TAA panel to a new panel of seven TAAs, consisting of p53, NY-ESO-1, CAGE, GBU4-5, SOX2, HuD, and MAGE A4. This seven-TAA panel showed a sensitivity and specificity of 41 and $91 \%$, respectively, with a positive predictive value of one in eight and $92 \%$ accuracy [72]. One issue is that some of these proteins alone are not specific to LC. As more research is conducted and more specific markers are discovered, it is hoped that an improvement will be seen in the accuracy and predictive value.

In another study looking for biomarkers in NSCLC, four differentially expressed proteins were identified between normal serum and serum from patients with NSCLC. These proteins were SMOX, NOLC1, MALAT1, and HMMR. When looked at alone, NOLC1 was the most significant, with sensitivity and specificity of 45 and $96.2 \%$, respectively. When all four markers were combined, positive predictive value was highest, with $66.7 \%$ sensitivity, $60 \%$ specificity, and $63.2 \%$ accuracy. When this data was applied to different stages of disease, the highest sensitivity was among stage III patients at $82.4 \%$, and lowest among stage IV patients at $50 \%$. Stage I and II patients had sensitivities of 63.6 and $62.5 \%$, respectively [73].

There is also new research focusing on microRNAs (miRNA), which are small noncoding RNA segments that are able to regulate gene expression [74]. Deregulation of miRNAs expression levels has been found in several human cancers, including lung [75]. Several studies have identified and evaluated different miRNAs as diagnostic and prognostic biomarkers in LC [76-80]. Bianchi and colleagues tested 34 miRNA obtained from serum samples in asymptomatic high-risk patients that showed $80 \%$ accuracy for detecting NSCLC [81]. While this remains promising, there are numerous miRNAs, with new ones still being identified, and further investigation is needed to validate this and other serum-biomarker testing.

Light Induced Fluorescence Endoscopy (LIFE)

Early detection and localization of endobronchial lesions remains a challenge in LC testing. While sputum cytology is capable of detecting occult LC, flexible bronchoscopy is then required to try and localize the lesion, which tends to be successful in only $29 \%$ of cases [82]. Light-induced fluorescence endoscopy (LIFE) is a system that delivers a pulse of white light and collects the reflected light, which is then spectrally analyzed. The number of oscillations over the wavelength range is related to nuclear size, and when an increased number of enlarged nuclei are detected, the tissue is classified as dysplastic [83]. This difference in fluorescence between normal and neoplastic tissue can improve the ability of conventional bronchoscopy to identify intraepithelial neoplasia [84-86].

In one multicenter trial, adding LIFE bronchoscopy to conventional white light bronchoscopy improved the sensitivity of detecting at least one lesion from 37.3 to $75 \%$, although there was no improvement in positive predictive value [87].

In another prospective study of high-risk patients, autofluorescence bronchoscopy (AFB) and spiral CT, in addition to sputum cytology, were performed for primary LC surveillance. Sputum cytology showed $33 \%$ sensitivity and $64 \%$ specificity for detecting metaplasia, and was unable to detect any carcinoma or carcinoma in situ. When compared with AFB, it failed to detect $100 \%$ of dysplastic lesions and $68 \%$ of metaplastic lesions that were detected by AFB. Pre-malignant changes were 3.16 times more likely to be present on AFB when spiral CT found peripheral lung nodules [88]. Unfortunately, bronchoscopy is limited by scope size, and is often unhelpful in visualizing distal endobronchial lesions.

\section{Airway Epithelial Markers}

Cigarette smoke is known to cause damage in the airway, and there is interest in identifying biomarkers that would help identify smokers and former smokers at high risk for developing LC. Spira and colleagues first identified an 80-gene biomarker that could distinguish smokers with and without LC using a DNA microarray capable of detecting smoking-induced changes in gene expression of airway epithelial cells. When this microarray was independently tested, it had an accuracy, sensitivity, and specificity of 83, 80 , and $84 \%$, respectively. When combined with cytopathology from bronchoscopy, the biomarker had $95 \%$ sensitivity and a $95 \%$ negative predictive value [89]. 
In small cell LC, there has been a focus on the sonic hedgehog (Shh) signaling for screening. Shh is necessary for normal lung development, and has also been found to be active within airway epithelium during acute airway injury repair. The signal increases during repair immediately prior to neuroendocrine differentiation and this pattern has been seen in a subset of small-cell LC cell lines [90]. Detection of an elevated level of Shh signaling in airway epithelium could suggest the possibility of early SCLC in a high-risk patient, before any tumors are detected.

\section{Conclusions}

The NLST showed a mortality reduction of $20 \%$ in those screened for LC with LDCT. There are, however, limitations to the generalizability of the findings of this trial, and future studies should track outcomes after population-based screening is implemented in the community setting. It is quite possible that the incorporation of newer diagnostic modalities-including exhaled breath VOCs, airway epithelial gene expression biomarkers or serum sampling for antibodies-into LC risk models and pulmonary nodule management algorithms could improve the efficacy of LDCT as part of a screening for LC in the future.

\section{Compliance with Ethics Guidelines}

Conflict of Interest Rolando Sanchez Sanchez, Nichole T. Tanner, Nasar A. Siddiqi, and Gerard A. Silvestri declare that they have no conflict of interest.

Human and Animal Rights and Informed Consent This article does not contain any studies with human or animal subjects performed by any of the authors.

\section{References}

Papers of particular interest, published recently, have been highlighted as:

- Of importance

•- Of major importance

1. Siegel R, Naishadham D, Jemal A. Cancer statistics, 2013. CA Cancer J Clin. 2013;63(1):11-30.

2. • Oken MM, Hocking WG, Kvale PA, Andriole GL, Buys SS, Church TR, et al. Screening by chest radiograph and lung cancer mortality: the prostate, lung, colorectal, and ovarian (PLCO) randomized trial. JAMA. 2011;306(17):1865-73. This is the largest prospective randomized control trial evaluating the efficacy of annual chest X-rays for lung cancer screening.

3. Strauss GM, Gleason RE, Sugarbaker DJ. Chest X-ray screening improves outcome in lung cancer. A reappraisal of randomized trials on lung cancer screening. Chest. 1995;107(6 Suppl):270S9S.
4. • Aberle DR, Adams AM, Berg CD, Black WC, Clapp JD, Fagerstrom RM, et al. Reduced lung-cancer mortality with lowdose computed tomographic screening. $N$ Engl J Med. 2011;365(5):395-409. The National Lung Screening Trial (NLST) is the largest randomized prospective multicenter trial evaluating low-dose CT scan for the screening of lung cancer. It is the first trial to demonstrate a significant reduction in mortality. .

5. Diederich S, Wormanns D, Heindel W. Lung cancer screening with low-dose CT. Eur J Radiol. 2003;45(1):2-7.

6. Henschke CI, Yankelevitz DF, Naidich DP, McCauley DI, McGuinness G, Libby DM, et al. CT screening for lung cancer: suspiciousness of nodules according to size on baseline scans. Radiology. 2004;231(1):164-8.

7. Kaneko M, Eguchi K, Ohmatsu H, Kakinuma R, Naruke T, Suemasu K, et al. Peripheral lung cancer: screening and detection with low-dose spiral CT versus radiography. Radiology. 1996;201(3):798-802.

8. Nawa T, Nakagawa T, Kusano S, Kawasaki Y, Sugawara Y, Nakata $\mathrm{H}$. Lung cancer screening using low-dose spiral CT: results of baseline and 1-year follow-up studies. Chest. 2002;122(1):15-20.

9. Sone S, Takashima S, Li F, Yang Z, Honda T, Maruyama Y, et al. Mass screening for lung cancer with mobile spiral computed tomography scanner. Lancet. 1998;351(9111):1242-5.

10. Swensen SJ, Jett JR, Hartman TE, Midthun DE, Mandrekar SJ, Hillman SL, et al. CT screening for lung cancer: five-year prospective experience. Radiology. 2005;235(1):259-65.

11. Henschke CI, McCauley DI, Yankelevitz DF, Naidich DP, McGuinness G, Miettinen OS, et al. Early lung cancer action project: overall design and findings from baseline screening. Lancet. 1999;354(9173):99-105.

12. Richardson A. Screening and the number needed to treat. J Med Screen. 2001;8(3):125-7.

13. Platt R, Takvorian SU, Septimus E, Hickok J, Moody J, Perlin J, et al. Cluster randomized trials in comparative effectiveness research: randomizing hospitals to test methods for prevention of healthcare-associated infections. Med Care. 2010;48(6 Suppl): S52-7.

14. • Wiener RS, Schwartz LM, Woloshin S, Welch HG. Populationbased risk for complications after transthoracic needle lung biopsy of a pulmonary nodule: an analysis of discharge records. Ann Intern Med. 2011;155(3):137-44. This is one of the largest cohorts in the United States evaluating the complications associated with transthoracic needle biopsy.

15. Tanner NT, Mehta H, Silvestri GA. New testing for lung cancer screening. Oncology (Williston Park). 2012;26(2):176-82.

16. Katz DA, Jarrard DF, McHorney CA, Hillis SL, Wiebe DA, Fryback DG. Health perceptions in patients who undergo screening and workup for prostate cancer. Urology. 2007;69(2): 215-20.

17. McNaughton-Collins M, Fowler FJ Jr, Caubet JF, Bates DW, Lee JM, Hauser A, et al. Psychological effects of a suspicious prostate cancer screening test followed by a benign biopsy result. Am J Med. 2004;117(10):719-25.

18. van Klaveren RJ, Oudkerk M, Prokop M, Scholten ET, Nackaerts $\mathrm{K}$, Vernhout R, et al. Management of lung nodules detected by volume CT scanning. N Engl J Med. 2009;361(23):2221-9.

19. Bach P, Cramer L, Schrag D, et al. The influence of hospital volume on survival after resection for lung cancer. N Eng J Med. 2001;345:181-8.

20. Silvestri G, Handy J, Lackland D, et al. Specialists achieve better outcomes than generalists for lung cancer surgery. Chest. 1998;114:675-80.

21. DE Midthun. Early diagnosis of lung cancer. F1000Prime Rep. 2013;5:12.

22. Boiselle PM. Computed tomography screening for lung cancer. JAMA. 2013;309(11):1163-70. 
23. Aberle DR, Abtin F, Brown K. Computed tomography screening for lung cancer: has it finally arrived? Implications of the national lung screening trial. Journal Clin Oncol. 2013;31(8):1002-8.

24. Takashima S, Maruyama Y, Hasegawa M, Yamanda T, Honda T, Kadoya M, et al. CT findings and progression of small peripheral lung neoplasms having a replacement growth pattern. AJR Am J Roentgenol. 2003;180(3):817-26.

25. Aoki $T$, Nakata $H$, Watanabe $H$, Nakamura $K$, Kasai T, Hashimoto $\mathrm{H}$, et al. Evolution of peripheral lung adenocarcinomas: CT findings correlated with histology and tumor doubling time. AJR Am J Roentgenol. 2000;174(3):763-8.

26. - Wilson DO, Ryan A, Fuhrman C, Schuchert M, Shapiro S, Siegfried JM, et al. Doubling times and CT screen-detected lung cancers in the Pittsburgh Lung Screening Study. Am J Respir Crit Care Med. 2012;185(1):85-9. This study showed that the incorporation of volumetric measures such as doubling could help distinguish between indolent and more aggressive lung cancers.

27. - Veronesi G, Maisonneuve P, Bellomi M, Rampinelli C, Durli I, Bertolotti R, et al. Estimating overdiagnosis in low-dose computed tomography screening for lung cancer: a cohort study. Ann Intern Med. 2012;157(11):776-84. This study also showed that the incorporation of volumetric measures such as doubling could help distinguish between indolent and more aggressive lung cancers.

28. - Maisonneuve P, Bagnardi V, Bellomi M, Spaggiari L, Pelosi G, Rampinelli $\mathrm{C}$, et al. Lung cancer risk prediction to select smokers for screening CT - a model based on the Italian COSMOS trial. Cancer Prev Res (Phila). 2011;4(11):1778-89. This trial suggests that the use of a multivariable risk model for lung cancer, including age, nodule characterisitics, smoking, FEVI, and emphysema on initial CT, could help to improve the efficacy of LDCT screening.

29. Silvestri GA, Nietert PJ, Zoller J, Carter C, Bradford D. Attitudes towards screening for lung cancer among smokers and their nonsmoking counterparts. Thorax. 2007;62(2):126-30.

30. Centers for Disease Control and Prevention (CDC). Vital signs: current cigarette smoking among adults aged $>$ or $=18$ yearsUnited States, 2009. MMWR Morb Mortal Wkly Rep. 2010;59(35): $1135-40$.

31. - Larke FJ, Kruger RL, Cagnon CH, Flynn MJ, McNitt-Gray $\mathrm{MM}, \mathrm{Wu} \mathrm{X}$, et al. Estimated radiation dose associated with lowdose chest CT of average-size participants in the National Lung Screening Trial. AJR Am J Roentgenol. 2011;197(5):1165-9. This study estimated the average effective radiation dose associated with LDCT in the NLST study population.

32. Brenner DJ, Hall EJ. Computed tomography—an increasing source of radiation exposure. N Engl J Med. 2007;357(22):2277-84.

33. Brenner DJ. Radiation risks potentially associated with low-dose CT screening of adult smokers for lung cancer. Radiology. 2004;231(2):440-5.

34. American College of Physicians. Information on cost-effectiveness: an essential product of a national comparative effectiveness program. Ann Intern Med. 2008;148(12):956-61.

35. Eichler HG, Kong SX, Gerth WC, Mavros P, Jonsson B. Use of cost-effectiveness analysis in health-care resource allocation decision-making: how are cost-effectiveness thresholds expected to emerge? Value Health. 2004;7(5):518-28.

36. Chirikos TN, Hazelton T, Tockman M, Clark R. Screening for lung cancer with CT: a preliminary cost-effectiveness analysis. Chest. 2002;121(5):1507-14.

37. Mahadevia PJ, Fleisher LA, Frick KD, Eng J, Goodman SN, Powe NR. Lung cancer screening with helical computed tomography in older adult smokers: a decision and cost-effectiveness analysis. JAMA. 2003;289:313-22.

38. Wisnivesky JP, Mushlin AI, Sicherman N, Henschke C. The costeffectiveness of low-dose CT screening for lung cancer: preliminary results of baseline screening. Chest. 2003;124(2): 614-21.

39. - McMahon PM, Kong CY, Bouzan C, Weinstein MC, Cipriano LE, Tramontano AC, et al. Cost-effectiveness of computed tomography screening for lung cancer in the United States. J Thorac Oncol. 2011;6(11):1841-8. This trial used a microsimulated model to evaluate the cost-effectiveness analysis of LDCT for lung cancer screening. The rate of smoking cessation at the time of screening was the most important factor predicting the cost-effective value.

40. van der Aalst CM, van den Bergh KA, Willemsen MC, de Koning HJ, van Klaveren RJ. Lung cancer screening and smoking abstinence: 2-year follow-up data from the Dutch-Belgian randomised controlled lung cancer screening trial. Thorax. 2010;65(7):600-5.

41. Cromwell J, Bartosch WJ, Fiore MC, Hasselblad V, Baker T. Cost-effectiveness of the clinical practice recommendations in the AHCPR guideline for smoking cessation. Agency for Health Care Policy and Research. JAMA. 1997;278(21):1759-66.

42. •• Humphrey LL, Deffebach M, Pappas M, Baumann C, Artis K, Mitchell JP, et al. Screening for lung cancer with low-dose computed tomography: a systematic review to update the U.S. Preventive services task force recommendation. Ann Intern Med. 2013;159(6):411-20. The results of this systematic review evaluating the benefits of LDCT in lung cancer screening were the basis for the new USPSTF recommendations for lung cancer screening.

43. Hakim M, Broza YY, Barash O, Peled N, Phillips M, Amann A, et al. Volatile organic compounds of lung cancer and possible biochemical pathways. Chem Rev. 2012;112(11):5949-66.

44. Amann A, Corradi M, Mazzone P, Mutti A. Lung cancer biomarkers in exhaled breath. Expert Rev Mol Diagn. 2011;11(2):207-17.

45. Mazzone PJ. Analysis of volatile organic compounds in the exhaled breath for the diagnosis of lung cancer. J Thorac Oncol. 2008;3(7):774-80.

46. Horvath I, Lazar Z, Gyulai N, Kollai M, Losonczy G. Exhaled biomarkers in lung cancer. Eur Respir J. 2009;34(1):261-75.

47. Gordon SM, Szidon JP, Krotoszynski BK, Gibbons RD, O’Neill HJ. Volatile organic compounds in exhaled air from patients with lung cancer. Clin Chem. 1985;31(8):1278-82.

48. Poli D, Carbognani P, Corradi M, Goldoni M, Acampa O, Balbi $\mathrm{B}$, et al. Exhaled volatile organic compounds in patients with non-small cell lung cancer: cross sectional and nested short-term follow-up study. Respir Res. 2005;6:71.

49. Phillips M, Altorki N, Austin JH, Cameron RB, Cataneo RN, Greenberg J, et al. Prediction of lung cancer using volatile biomarkers in breath. Cancer Biomark. 2007;3(2):95-109.

50. Di Natale C, Macagnano A, Martinelli E, Paolesse R, D'Arcangelo G, Roscioni C, et al. Lung cancer identification by the analysis of breath by means of an array of non-selective gas sensors. Biosens Bioelectron. 2003;18(10):1209-18.

51. - Mazzone PJ, Wang XF, Xu Y, Mekhail T, Beukemann MC, Na $\mathrm{J}$, et al. Exhaled breath analysis with a colorimetric sensor array for the identification and characterization of lung cancer. J Thorac Oncol. 2012;7(1):137-42. This study showed that the exhaled breath analysis using calorimetric sensor arrays could help identify and characterize lung cancer in patients.

52. Mazzone PJ, Hammel J, Dweik R, Na J, Czich C, Laskowski D, et al. Diagnosis of lung cancer by the analysis of exhaled breath with a colorimetric sensor array. Thorax. 2007;62(7):565-8.

53. Machado RF, Laskowski D, Deffenderfer O, Burch T, Zheng S, Mazzone PJ, et al. Detection of lung cancer by sensor array analyses of exhaled breath. Am J Respir Crit Care Med. 2005;171(11):1286-91.

54. Bajtarevic A, Ager C, Pienz M, Klieber M, Schwarz K, Ligor M, et al. Noninvasive detection of lung cancer by analysis of exhaled breath. BMC Cancer. 2009;9:348. 
55. Wehinger A, Schmid A, Mechtcheriakov S, Ledochowski M, Grabmer C, Gastl GA, et al. Lung cancer detection by proton transfer reaction mass-spectrometric analysis of human breath gas. Int J Mass Spectrom. 2007;265(1):49-59.

56. McCulloch M, Jezierski T, Broffman M, Hubbard A, Turner K, Janecki T. Diagnostic accuracy of canine scent detection in earlyand late-stage lung and breast cancers. Integr Cancer Ther. 2006; $5(1): 30-9$

57. - Buszewski B, Ligor T, Jezierski T, Wenda-Piesik A, Walczak M, Rudnicka J. Identification of volatile lung cancer markers by gas chromatography-mass spectrometry: comparison with discrimination by canines. Anal Bioanal Chem. 2012;404(1):141-6. This study showed that trained dogs could be able to discriminate breath samples of patients with and without lung cancer.

58. Boedeker E, Friedel G, Walles T. Sniffer dogs as part of a bimodal bionic research approach to develop a lung cancer screening. Interact Cardiovasc Thorac Surg. 2012;14(5):511-5.

59. Tu RH, Mitchell CS, Kay GG, Risby TH. Human exposure to the jet fuel, JP-8. Aviat Space Environ Med. 2004;75(1):49-59.

60. Kischkel S, Miekisch W, Sawacki A, Straker EM, Trefz P, Amann A, et al. Breath biomarkers for lung cancer detection and assessment of smoking related effects-confounding variables, influence of normalization and statistical algorithms. Clin Chim Acta. 2010;411(21-22):1637-44.

61. Cope KA, Watson MT, Foster WM, Sehnert SS, Risby TH. Effects of ventilation on the collection of exhaled breath in humans. J Appl Physiol. 2004;96(4):1371-9.

62. Chan HP, Lewis C, Thomas PS. Exhaled breath analysis: novel approach for early detection of lung cancer. Lung Cancer. 2009;63(2):164-8.

63. Chan HP, Tran V, Lewis C, Thomas PS. Elevated levels of oxidative stress markers in exhaled breath condensate. J Thorac Oncol. 2009;4(2):172-8.

64. Carpagnano GE, Foschino-Barbaro MP, Mule G, Resta O, Tommasi S, Mangia A, et al. 3p microsatellite alterations in exhaled breath condensate from patients with non-small cell lung cancer. Am J Respir Crit Care Med. 2005;172(6):738-44.

65. Carpagnano GE, Foschino-Barbaro MP, Spanevello A, Resta O, Carpagnano $F$, Mule $G$, et al. $3 p$ microsatellite signature in exhaled breath condensate and tumor tissue of patients with lung cancer. Am J Respir Crit Care Med. 2008;177(3):337-41.

66. Gessner C, Kuhn H, Toepfer K, Hammerschmidt S, Schauer J, Wirtz H. Detection of p53 gene mutations in exhaled breath condensate of non-small cell lung cancer patients. Lung Cancer. 2004;43(2):215-22.

67. Carpagnano GE, Foschino-Barbaro MP, Resta O, Gramiccioni E, Carpagnano F. Endothelin-1 is increased in the breath condensate of patients with non-small-cell lung cancer. Oncology. 2004; 66(3):180-4.

68. Carpagnano GE, Resta O, Foschino-Barbaro MP, Gramiccioni E, Carpagnano F. Interleukin-6 is increased in breath condensate of patients with non-small cell lung cancer. Int $\mathrm{J}$ Biol Marker. 2002;17(2):141-5.

69. Carpagnano GE, Spanevello A, Curci C, Salerno F, Palladino GP, Resta O, et al. IL-2, TNF-alpha, and leptin: local versus systemic concentrations in NSCLC patients. Oncol Res. 2007;16(8):375-81.

70. Turk MJ, Wolchok JD, Guevara-Patino JA, Goldberg SM, Houghton AN. Multiple pathways to tumor immunity and concomitant autoimmunity. Immunol Rev. 2002;188:122-35.

71. Boyle P, Chapman CJ, Holdenrieder S, Murray A, Robertson C, Wood WC, et al. Clinical validation of an autoantibody test for lung cancer. Ann Oncol. 2011;22(2):383-9.

72. Chapman CJ, Healey GF, Murray A, Boyle P, Robertson C, Peek LJ, et al. EarlyCDT(R)-Lung test: improved clinical utility through additional autoantibody assays. Tumour Biol. 2012;33(5):1319-26.
73. Yao Y, Fan Y, Wu J, Wan H, Wang J, Lam S, et al. Potential application of non-small cell lung cancer-associated autoantibodies to early cancer diagnosis. Biochem Biophys Res Commun. 2012;423(3):613-9.

74. Calin GA, Croce CM. MicroRNA-cancer connection: the beginning of a new tale. Cancer Res. 2006;66(15):7390-4.

75. Markou A, Sourvinou I, Vorkas PA, Yousef GM, Lianidou E. Clinical evaluation of microRNA expression profiling in nonsmall cell lung cancer. Lung Cancer. 2013;81(3):388-96.

76. Yu SL, Chen HY, Chang GC, Chen CY, Chen HW, Singh S, et al. MicroRNA signature predicts survival and relapse in lung cancer. Cancer Cell. 2008;13(1):48-57.

77. Saito M, Schetter AJ, Mollerup S, Kohno T, Skaug V, Bowman $\mathrm{ED}$, et al. The association of microRNA expression with prognosis and progression in early-stage, non-small cell lung adenocarcinoma: a retrospective analysis of three cohorts. Clin Cancer Res. 2011;17(7):1875-82.

78. Markou A, Tsaroucha EG, Kaklamanis L, Fotinou M, Georgoulias V, Lianidou ES. Prognostic value of mature microRNA-21 and microRNA-205 overexpression in non-small cell lung cancer by quantitative real-time RT-PCR. Clin Chem. 2008;54(10): 1696-704.

79. Duncavage E, Goodgame B, Sezhiyan A, Govindan R, Pfeifer J. Use of microRNA expression levels to predict outcomes in resected stage I non-small cell lung cancer. J Thorac Oncol. 2010;5(11): 1755-63.

80. Bishop JA, Benjamin H, Cholakh H, Chajut A, Clark DP, Westra WH. Accurate classification of non-small cell lung carcinoma using a novel microRNA-based approach. Clin Cancer Res. 2010;16(2):610-9.

81. Bianchi F, Nicassio F, Marzi M, Belloni E, Dall'olio V, Bernard $\mathrm{L}$, et al. A serum circulating miRNA diagnostic test to identify asymptomatic high-risk individuals with early stage lung cancer. EMBO Mol Med. 2011;3(8):495-503.

82. Woolner LB, Fontana RS, Cortese DA, Sanderson DR, Bernatz PE, Payne WS, et al. Roentgenographically occult lung cancer: pathologic findings and frequency of multicentricity during a 10-year period. Mayo Clin Proc. 1984;59(7):453-66.

83. Wallace MB, Perelman LT, Backman V, Crawford JM, Fitzmaurice M, Seiler M, et al. Endoscopic detection of dysplasia in patients with Barrett's esophagus using light-scattering spectroscopy. Gastroenterology. 2000;119(3):677-82.

84. Hung J, Lam S, LeRiche JC, Palcic B. Autofluorescence of normal and malignant bronchial tissue. Lasers Surg Med. 1991;11(2):99-105.

85. Lam S, MacAulay C, Hung J, LeRiche J, Profio AE, Palcic B. Detection of dysplasia and carcinoma in situ with a lung imaging fluorescence endoscope device. J Thorac Cardiovasc Surg. 1993;105(6):1035-40.

86. Lam S, Macaulay C, Leriche JC, Ikeda N, Palcic B. Early localization of bronchogenic carcinoma. Diagn Ther Endosc. 1994;1(2):75-8.

87. Lam S, Kennedy T, Unger M, Miller YE, Gelmont D, Rusch V, et al. Localization of bronchial intraepithelial neoplastic lesions by fluorescence bronchoscopy. Chest. 1998;113(3):696-702.

88. Loewen G, Natarajan N, Tan D, Nava E, Klippenstein D, Mahoney $\mathrm{M}$, et al. Autofluorescence bronchoscopy for lung cancer surveillance based on risk assessment. Thorax. 2007;62(4):335-40.

89. Spira A, Beane J, Shah V, Liu G, Schembri F, Yang X, et al. Effects of cigarette smoke on the human airway epithelial cell transcriptome. Proc Natl Acad Sci USA. 2004;101(27):10143-8.

90. Watkins DN, Berman DM, Burkholder SG, Wang B, Beachy PA, Baylin SB. Hedgehog signalling within airway epithelial progenitors and in small-cell lung cancer. Nature. 2003;422(6929):313-7. 